\title{
EXTENDED WINTERS ENTAIL LONG-TERM COSTS FOR INSECT OFFSPRING REARED IN AN OVERWINTER BURROW
}

Maximilian Körner ${ }^{1} \#$, Susanne Foitzik ${ }^{1}$, Joël Meunier ${ }^{1,2}$

${ }^{1}$ Institute of Organismic and Molecular Evolutionary Biology, Johannes-Gutenberg University of Mainz, Mainz, Germany

${ }^{2}$ Institut de Recherche sur la Biologie de I'Insecte, UMR 7261, CNRS, François-Rabelais University of Tours, Tours, France

\# Corresponding author: Maximilian Körner

Email: maxkoerner@gmx.net

Tel.: +49 $613139-27853$

Fax: $+49613139-27850$ 


\section{ABSTRACT}

Winter imposes an ecological challenge to animals living in colder climates, especially if these adverse conditions coincide with reproduction and offspring rearing. To overcome this challenge, some insects burrow in the soil to protect adults, larvae, or eggs from negative effects of winter. However, whether this protection is effective against any long-term consequences of changes in winter duration is unclear. Here, we investigated the long-term effects of winter length variation on eggs of the European earwig Forficula auricularia. In this insect, females construct and maintain a burrow between late autumn and spring, in which they provide extensive forms of care to their eggs and then juveniles. We experimentally maintained earwig females under two winter durations of either four or six weeks and examined the resulting effects in terms of 1) hatching date, 2) developmental time of juveniles until adulthood, 3) adult mass at emergence, and 4) investment of adult offspring females in three key immune parameters: hemocyte concentration, phenoloxidase, and prophenoloxidase activities. Because earwigs' resistance against pathogens relies on their social environment, effects of winter length on immunity were tested on females exposed to different social environments: with familiar conspecifics, unfamiliar conspecifics, or in isolation. Our results reveal that after the winter treatments, eggs reared in short winters hatched earlier and the emerging juveniles reached adulthood faster than juveniles from eggs exposed to long winters. We also showed that prophenoloxidase was $30 \%$ higher in females from the long compared to short winter treatment, regardless of social environment. Finally, we found that hemocyte counts where twice as high in short compared to long winter females, but only with unfamiliar conspecifics. Overall, our study reveals that maintaining and caring for eggs in a burrow does not prevent the costs associated with increased winter duration. Keywords: Diapause; Egg gestation; Winter; Insects; Immunity; Sub-social

\section{INTRODUCTION}

Winter can be a major challenge to all animals living in temperate and cold climates. Both the severity and duration of winter alter many life history traits, such as size and time of first reproduction (Altizer et al., 2006; Fretwell, 1972), as well as affect the mobility and metabolism of individuals from many species and taxa (Adamczewski et al., 1993; Bale, 1987; Danks, 2000; Lee Jr., 1991). Moreover, winter often reduces the availability of resources for overwintering individuals, generally resulting in food deprivation, desiccation, and increased mortality (Danks, 2000; Lee and Dellinger, 1991; Sperry and Weatherhead, 2012; Williams et al., 2015).

Ectotherms are often considered particularly sensitive to changes in temperature during winter because they cannot regulate their body temperature physiologically (Huey, 1976). While this lack of regulation often explains the severely limited geographic range of many vertebrate ectotherms (Buckley et al., 2012), invertebrate ectotherms - and insects in particular - can be found in surprisingly many cold climates (Downes, 1965; Turnock and Fields, 2005), indicating that they have evolved adaptations to endure and thrive in the cold (Lee and Dellinger, 1991). These adaptations are generally divided into physiological mechanisms that allow them to either avoid or tolerate freezing (Bale, 1987; Lee and Dellinger, 1991; Sinclair, 2015; Zachariassen, 1985), and into behavioral strategies involving seeking out protective microhabitats such as shelter below tree bark, rocks, or in constructed burrows (Baer and Schmid-Hempel, 2005; Baust, 1976; Danks, 2002; Gehrken, 1984; Sinclair, 2001).

Burrowing into the soil and remaining inactive to avoid sub-zero temperatures has been well-studied in a number of insect species (Danks, 2002), such as carabid and crysomelid beetles 
(Costanzo et al., 1997; Montero and Lietti, 1998) and noctuid moth larvae (O'Brien and Kurczewski, 1982; Young and Price, 1977). While these strategies are often accompanied by preprogrammed or environmentally queued states of energy conservation involving metabolic changes such as dormancy, quiescence or diapause (Hahn and Denlinger, 2011; Koštál, 2006), some species remain surprisingly active in their burrow, such as the European earwig which continually provides maternal care (Lamb, 1976). In these species, such an activity is expected to be costly to the fitness of an individual (e.g. due to cannibalistic consumption of eggs or increased mortality) and thus lead to important trade-offs between the benefits of protection from cold and energy conservation on one hand, and the ability to perform complex behaviors such as parental care toward overwintering eggs on the other hand (Clarke et al., 2013; Danks, 2002; Koch and Meunier, 2014; Ruf et al., 2012).

The success of ectotherm overwintering, however, is not only tied to the degree of winter cold, but also to its duration (Colinet et al., 2015; Lee and Dellinger, 1991). In species that cease feeding during overwintering, and thus determine their investment into cryoprotective and/or energy reserves at the beginning of winter, longer winters can lead to energy depletion and lower winter survival rates (Han and Bauce, 1998; Morris and Fulton, 1970). Furthermore, prolonged cold can lead to an accumulation of chilling injuries, which can further decrease survival either on their own or in interaction with energy depletion (Koštál, 2006; Sinclair, 2015). Finally, since individual metabolism and performance depend on the thermal conditions experienced during development, the duration of cold periods is expected to shape adult performance of offspring reared during winter (Le Lann et al., 2011).

The duration of winter length is often a flexible parameter, which varies not only between geographic locales, but also from year to year (Bonan, 2015). Interestingly, the accelerating global climate change reported over the last decades is a novel major cause of changes in mean temperature and season duration across the planet, which may profoundly shape the phenology and abundance of many plant and animal species (Butler and Tran, 2017; Estrella and Menzel, 2013; Parmesan, 2006; Princé and Zuckerberg, 2015; Ramseyer et al., 2009; Stålhandske et al., 2015; Vitasse et al., 2017; Williams et al., 2017).

In this study, we investigate whether winter duration has long-term effects on offspring of the European earwig, Forficula auricularia, a hemimetabolous cosmopolitan insect exhibiting pre- and post-hatching maternal care (Kölliker, 2007; Meunier et al., 2012). In this species, females provide pre-hatching care by constructing a burrow in late autumn or early winter to lay their eggs and overwinter with the clutch until hatching occurs in early spring (Koch and Meunier, 2014; Lamb, 1976). Over the course of winter, females cease to feed but continuously groom their eggs to prevent the growth of pathogenic fungi, a behavior crucial to reproductive success (Boos et al., 2014; Diehl et al., 2017). This species is native to Eurasia but has reached nearly worldwide distribution as an invasive species, for example in North America and the Falkland Islands (Langston and Powell, 1975; Maczey et al., 2016). This widespread occurrence suggests that the species is able to adapt to a variety of winter conditions, but little is known about the effects of winter phenology. Additionally, seasonality is expected to affect reproduction in this species, as females can produce a second clutch in spring and the likelihood of producing a second clutch is generally higher in populations from warmer climates (Meunier et al., 2012; Ratz et al., 2016).

In our experimental setup, earwig clutches were experimentally kept under winter conditions $\left(5^{\circ} \mathrm{C}\right)$ for either 33 or 47 days to reveal whether winter duration has any subsequent effect on important life history traits in the offspring upon reaching adulthood. The difference in 
cold period length represents recorded phenological shifts in the study animals' home range between 1950 and 2001 (Linderholm, 2006). Specifically, we were interested in whether winter length determines 1) the hatching date of the eggs, 2) the developmental speed of the juveniles (called nymphs) into adults, 3) the mass of the adults, and 4) the immune-competence of the resulting adult offspring. Because a recent study revealed that resistance against pathogens of earwig adults at least partly relies on their social environment (Kohlmeier et al., 2016), exploring the effects of winter length on earwig immunity required us to control for their social environment. To this end, the adult females were exposed to different social environments consisting of females being maintained in groups with either constant or changing group members, or suddenly isolated after long-term group living. Note that we chose to only investigate females because immune expression in males of this species may be affected by their tendency to engage in combat, as well as by reported trade-offs with their conspicuous weaponry (Körner et al., 2017). Female immune-competence was measured using three key components of insect immunity: phenoloxidase activity (PO), prophenoloxidase activity (PPO; which is measured together with PO as total-PO), and hemocyte concentration (Gillespie et al., 1997; Körner et al., 2017; Lavine and Strand, 2002; Strand and Pech, 1995). In insect immunity, PO mediates the melanization of foreign objects and the release of cytotoxic agents through the activation of PPO, its inactive precursor mostly stored in the hemolymph and the hemocytes (Cerenius and Söderhäll, 2004). Hemocytes are immune cells suspended in the hemolymph that are involved in recognizing and encapsulating pathogens (Lavine and Strand, 2002).

We expected that long winters would slow down egg development, as low-temperature conditions can arrest development in insect eggs (Tatar and Yin, 2001). Phenological shifts during early life-stages may not necessarily carry over to later stages (Salis et al., 2017), so we predicted no difference in developmental time from nymph to adult, which typically takes two months but can vary slightly between populations (see Ratz et al. 2016). While insect immunity is known to vary with season and temperature and can directly trade-off with cold responses, these relationships seem largely species dependent, and how these trade-offs affect developing insects in the long-term is yet unclear (Ferguson and Sinclair, 2017; Linderman et al., 2012). Given the importance of early development for life history traits, we expected adults' immune competence to reflect any development trade-offs compensating for the phenological shift between the two winter treatments. Finally, in line with previously shown immune-sensitivity to changes in the social environment (Kohlmeier et al., 2016), we expected adults to reflect challenged immunity when living in changing group compositions compared to constant groups.

\section{MATERIALS AND METHODS}

\subsection{Animal origin \& winter treatments}

We caught F. auricularia adults in July-August 2015 in Mainz, Germany (4958'20.5"N $8^{\circ} 11^{\prime} 42.3^{\prime \prime E}$ ). Immediately after field sampling, we distributed these field-caught individuals among 36 plastic terraria $(37 \times 22 \times 25 \mathrm{~cm})$, which were grounded with moist sand and cardboard shelters and kept at $18^{\circ}-20^{\circ} \mathrm{C}$ dark:light. These animals were allowed to mate freely from August $15^{\text {th }}$ to November $12^{\text {th }}$. After that time, each female (approx. 1500 individuals) was isolated in a Petri dish $(\varnothing 9 \mathrm{~cm})$ to mimic natural dispersion and encourage egg production (Lamb 1975). The Petri dishes were setup with moist sand and maintained in constant darkness. Each female was provided with an ad libitum amount of food (artificial diet mainly consisting of pollen, cat food, wheat germ, and agar; see details in Kramer et al., 2015), renewed once per week. Immediately 
after isolation, temperatures were sequentially decreased to initiate winter conditions: 7 days at $15^{\circ} \mathrm{C}, 7$ days at $10^{\circ} \mathrm{C}, 7$ days at $8^{\circ} \mathrm{C}$ and finally, 33 days at $5^{\circ} \mathrm{C}$. At this point, we haphazardly selected half ( 650$)$ of the females ("short winter") to immediately enter the sequential warm-up phase ( 7 days at $8^{\circ} \mathrm{C}, 7$ days at $10^{\circ} \mathrm{C}$, and then maintained at $15^{\circ} \mathrm{C}$ until egg hatching), while the other half ("Iong winter") spent an additional 14 days at $5^{\circ} \mathrm{C}$ prior to entering the warm-up phase (for an exact timetable see Figure 1). From the day of egg laying, each clutch was monitored daily to check for emerged offspring. Egg hatching is generally well synchronized within a clutch and all offspring typically emerge within a day (Meunier and Kölliker, 2013). The hatching date for each clutch was noted. Following egg hatching, females and their offspring were moved to a climate chamber, where they were subjected to standard summer conditions (18-20 ${ }^{\circ} \mathrm{C} \mathrm{D:L}$ ) and provided with ad libitum food (conditions detailed in Kramer et al. 2015). Upon reaching adulthood, males and females were separated to prevent uncontrolled sib-mating (Meunier and Kölliker, 2013). Note that because females cease feeding during egg care (Meunier et al., 2012), the food present in each Petri dish at egg laying was removed and no fresh food was provided until egg hatching.

\subsection{Experimental setup}

We investigated the effects of varying winter length on offspring development and several life history traits of adult female earwigs. We first measured the hatching date and development time of juveniles into adults. To this end, we recorded the dates of egg hatching and the number of days between egg hatching and the final molt into adulthood in 177 haphazardly selected unrelated females (short winter $n=90$, long winter $n=87$ ). We then manipulated the social environment of the adult females to test whether winter length shaped socially induced changes in their immune competence. To this end, we haphazardly selected a subset of 123 unrelated females (short winter $n=65$, long winter $n=58$, all unrelated) two weeks after their final molt. Each of these females (hereafter called "focal females") were isolated for two weeks, then transferred to a new Petri dish with a group of three unfamiliar and unrelated females (hereafter called "nonfocal females").

The two-week timespan was chosen to allow the non-focal females to acclimate to their new group environment. Just before joining their conspecifics, each focal female was weighed to the nearest $0.001 \mathrm{mg}$ using a microbalance (model MYA5; PESCALE, Bisingen, Germany). Conversely, the non-focal females were haphazardly selected at the same time as the focal females, and were of the same developmental age - i.e. had been adults for about the same time as the focals (varying by 3 days max.). All non-focal females were marked by removing one of their two elytra (wing cover) tips under brief $\mathrm{CO}_{2}$-anaesthetization, which made it easy to distinguish non-focals from the focal females (elytra tips bear a clear, white spot in this species). Within a non-focal group, we always cut the same elytra but alternated the elytra side (left or right) between each replicate.

The goal of introducing our focal females to non-focals was to obtain the four following treatments: 1) familiar group unmanipulated, 2) familiar group manipulated, 3) changing group, and 4) sudden isolation. In the "familiar group unmanipulated" treatment, focal females were left with the initial group of non-focals and underwent no manipulations whatsoever until the measurements at the end of the experiment. In the "familiar group manipulated" treatment, focal females were manipulated (removed and re-introduced) after days 7, 14, and 21 to encounter the same group of non-focal females. In the "changing group" treatment, focal females were manipulated after days 7, 14, and 21 to encounter a new, unfamiliar group of three non-focal females. Finally, in the "sudden isolation" treatment, focal females were manipulated to 
encounter a new, unfamiliar group at day 7 and 14, and were then maintained in isolation from day 21 onward. For treatments "group change", "familiar group manipulated" and "sudden isolation", each new group encounter was done by moving the focal female into a new Petri dish, limiting her access to the new environment under a plastic containment for 10 minutes, subsequently adding the three non-focal females to the Petri dish, and finally removing the plastic containment. Finally, twenty-four hours after the last group encounter (or isolation), we measured the investment into three key immune parameters (see below) in each of the focal females.

\subsection{Immunity assays}

We measured three key immunity parameters in 112 females ( 6 females died during the experiment, 5 yielded insufficient hemolymph amounts) after the 22 days of social treatments: the Phenoloxidase activity (PO), Phenol- and Prophenoloxidase activity (total-PO), and the hemocyte concentration. The measurements were done following a standard protocol developed in earwigs (Vogelweith et al., 2017). In brief, we extracted hemolymph from each focal individual by piercing the soft cuticle between the $5^{\text {th }}$ and $6^{\text {th }}$ dorsal armor segments with a sterilized needle. We then used a chilled sterile capillary to extract $1 \mu$ of hemolymph per individual from the wound, which was immediately diluted in $25 \mu \mathrm{l}$ of cold sodium cacodylate $/ \mathrm{CaCl}_{2}$ buffer. Of this mixture, $10 \mu \mathrm{l}$ were used right away to count the circulating haemocytes using a Neubauer Improved Haemocytometer and a microscope (magnification $x$ 400), while the remaining $16 \mu l$ were frozen to later measure PO and total-PO. The PO and total-PO enzyme activities were spectrophotometrically measured using a standard protocol (Körner et al., 2017). Specifically, the frozen hemolymph-buffer sample was thawed on ice and centrifuged for 5 minutes at $4^{\circ} \mathrm{C}(4000$ $\times \mathrm{g}$ ) before pipetting $5 \mu \mathrm{l}$ of the resulting supernatant to a microplate well containing $20 \mu \mathrm{l}$ of PBS, $20 \mu \mathrm{l}$ of L-dopa solution (Sigma D-9628; $4 \mathrm{mg} / \mathrm{ml}$ of distilled water), and either $140 \mu$ l of distilled water (PO activity) or $140 \mu$ of chymotrypsin solution (Sigma C-7762, $0.07 \mathrm{mg} / \mathrm{ml}$ of distilled water; total-PO activity). The enzymatic reaction was then photometrically recorded for $2 \mathrm{~h} 47 \mathrm{~min}$ at $30^{\circ} \mathrm{C}$ in a microplate reader (Thermo scientific Multiskan ${ }^{\mathrm{TM}}$ FC Microplate Photometer). Enzymatic activity was defined as the slope of the reaction curve during the linear phase of the reaction (Vmax value: change in absorbance units/min) and measured using the free R-based program PO-CALC (Kohlmeier et al., 2015). To control for the effect of body size on immune functions, each focal female was weighed to the nearest $0.001 \mathrm{~g}$ using a microbalance (MYA5; PESCALE Bisingen, Germany) prior to hemolymph extraction.

\subsection{Statistical analyses}

We conducted all statistical analyses using the software R v3.4.3 loaded with the packages car, multcomp, and emmeans. We first tested whether our manipulation of winter length caused a difference in hatching date by comparing the days of egg hatching from the long and short winter treatments. Note that these days were relative to the first hatching date, i.e. values of 5 and 25 correspond to clutches that hatched 5 and 25 days after the first clutch that hatched in the entire experiment, respectively. We then employed two additional $t$-tests to compare the development time from hatching to adulthood as well as the female mass at the start of the experiment between the winter treatments.

The immune measurements were analyzed using three general linear models (GLM), in which the response variable was one of the three immune parameters (hemocyte concentration, PO activity, or total-PO activity), the two explanatory factors were the social treatments and 
winter treatments (short or long winter) and female mass at hemolymph extraction was entered as a covariate to control for any effects of female mass on their immunity. When significant, the interactions between treatments were further investigated using post-hoc least-squares means corrected for multiple testing (Tukey method; emmeans package). To fulfil homoscedasticity and Gaussian distribution of the model residuals, all models were computed using the square roottransformed hemocyte concentration and log+0.001-transformed PO and total-PO activities.

\section{RESULTS}

\subsection{Life history traits}

Overall, manipulating winter duration shaped egg and juvenile development, as well as adult female mass. In particular, short winters were associated with both earlier egg hatching $\left(\mathrm{t}_{162}=\right.$ 19.38, $\mathrm{P}<0.001$; Figure 2a) and shorter development time from egg hatching to adult emergence $\left(t_{162}=3.70, P<0.001 ;\right.$ Figure $\left.2 b\right)$. Additionally, short winter females were heavier than long winter females ( $\mathrm{t}_{175}=-2.89, \mathrm{P}=0.0043$; Figure $2 \mathrm{c}$ ).

\subsection{Immunity assays}

Females from the short winter treatment showed a lower total-PO activity than females from the long winter treatments, independent of the social treatment (Table 1, Figure 3). By contrast, the effect of winter length on the number of circulating hemocytes in the females' hemolymph depended on the social treatment (significant interactions shown in Table 1). Specifically, females from the short winter treatment showed a higher hemocyte count than females from the long winter treatment only when they were confronted with a changing group composition (Figure 4; Tukey post-hoc test, $\mathrm{P}=0.017$; Table 2). Finally, there were no effects of either winter length or social treatments on the PO activity of females (Table 1).

\section{DISCUSSION}

In our study, we investigated the effects of variation in winter length during early development on hatching date, development time, mass, and adult immunity in lab-reared female offspring of the European earwig. We report that longer winters cause a clear shift in both hatching date and development time: juveniles from the long winter treatment hatched later and took more time than short winter individuals from their first developmental instar to adulthood. Moreover, adult offspring females were heavier after the short compared to long winter treatment. We also found an interaction between the winter length and social environment on adult immunity. Specifically, females reared in the short winter treatment had a higher hemocyte count than long winter females, but only when the females encountered a changing group composition. On the other hand, females from the long winter treatment exhibited an overall higher combined phenoloxidase- and prophenoloxidase activity (total-PO) than females from the short winter treatment. We detected no differences in phenoloxidase activity (PO).

In line with our predictions, female offspring in the long winter treatment hatched later than those in the short winter treatment. In this species, egg development seems to be arrested during low temperature conditions and then advances quickly once temperatures increase (M. Körner, pers. observation). This delay in development could either represent a direct consequence of suboptimal thermal conditions (i.e. Marshall and Sinclair, 2015) or an adaptation to avoid unfavorable environmental conditions (Hodek and Hodková, 1988; Tauber and Tauber, 1976). By reducing or arresting developmental speed, the individual eggs may retain more energy not just for survival but also for the crucial post-hatching growth phase. Conversely, early 
emergence in low temperatures would likely result in high mortality and stunted development (Colinet et al., 2015). In many insect species overwintering in a dormant or quiescent state, such periods of energy conservation and diapause are often regulated by photoperiods (Koštál, 2006; Schebeck et al., 2017). In our study, the developing earwig eggs were maintained in constant darkness, reflecting their subterranean microhabitats in nature (Lamb, 1976). Thus, it seems that mainly temperature is responsible for triggering the arrest and continuation of development in overwintering eggs of the European earwig, suggesting that global warming could play a major role in the biology of this species (and its reproductive cycles) over the next decades.

Our data show that individuals reared during a longer winter not only hatched later, but also needed longer to reach adulthood. Such a long-term effect of temperature change and/or phenological shifts on offspring development is not ubiquitous among insects overwintering during developmental stages. For example, studies on tettigoniid species report an adaptive increase in developmental speed following longer cold periods (Ingrisch, 1985) and a recent study in the winter moth Operophtera brumata reports that shifts in early development can be at least partially compensated in subsequent development stages (Salis et al., 2017). Interestingly, such adaptations are typically associated with important fitness costs. For instance, an accelerated development due to shorter and/or milder winters can reduce adult body mass in the glassworm Chaoborus crystallinus (Büns and Ratte., 1991) and to reduce adult body size and fecundity in the Rocky Mountain butterfly Parnassius smintheus (Matter et al., 2011). Contrary to these findings, our results indicate an overall positive effect of shorter winter periods, as a shorter juvenile phase likely results in decreased predation, parasite pressure as well as overall mortality (Williams, 1999). This calls for further empirical studies exploring the nature and importance of these apparent benefits on long-term reproductive success in earwigs.

We found that short winter females exhibited higher hemocyte counts than females from the long winter treatment, but only in social environments with changing group members. Given the potential threat of infection through new group members, the increased hemocyte count likely reflects an increased ability to react to immune challenges (Lavine and Strand, 2002; Poyet et al., 2013; Vogelweith et al., 2013). Higher investment into immune traits is often linked to favorable conditions during development (Vogelweith et al., 2017), and hemocyte performance has in turn been positively associated with insect overwinter survival (Krams et al., 2011) further indicating a positive long-term effect of shorter winters. Interestingly, such positive effects appear to be masked under any other social treatment: neither constant group members nor the sudden loss of the social environment affected the circulating hemocyte count. The disruption of social bonds therefore appears to have a primary role in females' investment into hemocyte number, which emphasizes the importance of (disrupted) social environments in individual defenses against pathogens in social insects (Kohlmeier et al., 2016).

Long winter females showed an overall higher total-PO activity, independent of social treatment. The expression of PO/total-PO is notoriously difficult to interpret, as high levels of expression are not only harmful to infectious agents, but also to the host itself (González-Santoyo and Córdoba-Aguilar, 2012; Sadd and Siva-Jothy, 2006). In our laboratory setup, we can safely exclude the possibility of additional pathogen pressure in the long winter treatment. Our results therefore suggest that the overall higher expression of total-PO reflects the higher capability of short winter compared to long winter females to deal with the associated costs. More generally, the apparent discrepancy between our results on hemocyte concentration, total-PO, and PO activities emphasizes that variation in winter duration entails an important stress on female 
offspring, which later shapes their investment into some components of their immune system (Adamo, 2012) that do not necessarily correlate (i.e. Körner et al., 2017). Note that even if the three measures of potential immunity we present do not always reflect an individuals' ability to fight off an infection (González-Santoyo and Córdoba-Aguilar, 2012; Laughton et al., 2017), they nevertheless demonstrate that variation in winter length during egg development entails longterm physiological consequences in the resulting adults.

While this study does not specifically identify which mechanisms underlie the reported effects of winter duration in earwigs, our results suggest either a) a disruption of key processes during embryonal gestation in the eggs or b) an adaptation to natural phenological variations with life-long consequences for life history traits. In support of the first hypothesis, the conditions of winter dormancy have been identified as critical for both adult and developing individuals in several species, including burrowing ones (Costanzo et al., 1997; Han and Bauce, 1998; Matter et al., 2011). However, given the cosmopolitan distribution of the European earwig and its population-dependent ability to produce a second clutch during spring (Meunier et al., 2012; Ratz et al., 2016), it is also possible that mid-development adaptations to changed climatic conditions could be triggered by either the guarding mother or processes in the eggs themselves. Future studies comparing the egg development on a biochemical and transcriptional level in eggs from different climate zones and populations may help to disentangle these two hypotheses.

\section{CONCLUSION}

Overall, we demonstrate that rearing offspring under variable cold periods during winter can entail long-term consequences not only in terms of development and growth, but also in terms of immune responses. In particular, our results indicate that prolonged overwintering during early development results in offspring showing slower development and reduced socially-induced immune capacity, but higher overall levels of costly constitutive cytotoxic immune activity. While this may indicate a generally lower offspring quality caused by a prolonged egg phase, whether these effects represent hampered development or are in fact an adaptation to harsher conditions remains unknown. More generally, our study underlines the importance of investigating the effects of climate variations on the gestation and development of overwintering insect species in a time of climate change.

\section{Data availability}

The full corresponding dataset to this manuscript will be made available upon publication via Mendeley Data.

\section{Acknowledgements}

We would like to thank Dr. Rebecca Nagel for her help with improving the manuscript.

\section{Funding sources}

This study has been financed by the German Science Foundation (DFG; ME4179/3-1 to JM).

\section{References}

Adamczewski, J.Z., Hudson, R.J., Gates, C.C., 1993. Winter Energy-Balance and Activity of Female Caribou on Coats-Island, Northwest-Territories - the Relative Importance of Foraging and 
Body Reserves. Can. J. Zool. Can. Zool. 71, 1221-1229.

Adamo, S.A., 2012. The effects of the stress response on immune function in invertebrates: An evolutionary perspective on an ancient connection. Horm. Behav. 62, 324-330.

Altizer, S., Dobson, A., Hosseini, P., Hudson, P., Pascual, M., Rohani, P., 2006. Seasonality and the dynamics of infectious diseases. Ecol. Lett. 9, 467-484.

Baer, B., Schmid-Hempel, P., 2005. Sperm influences female hibernation success, survival and fitness in the bumble-bee Bombus terrestris. Proc. R. Soc. B Biol. Sci. 272, 319-323.

Bale, J.S., 1987. Insect cold hardiness: Freezing and supercooling-An ecophysiological perspective. J. Insect Physiol. 33, 899-908.

Baust, J.G., 1976. Temperature buffering in an arctic microhabitat. Ann. Entomol. Soc. Am. 69, 117-119.

Bonan, G., 2015. Ecological Climatology: Concepts and Applications, 3rd ed. Cambridge University Press, Cambridge.

Boos, S., Meunier, J., Pichon, S., Kölliker, M., 2014. Maternal care provides antifungal protection to eggs in the European earwig. Behav. Ecol. 25, 1-8.

Buckley, L.B., Hurlbert, A.H., Jetz, W., 2012. Broad-scale ecological implications of ectothermy and endothermy in changing environments. Glob. Ecol. Biogeogr. 21, 873-885.

Büns, M., Ratte., H.T., 1991. The combined effects of temperature and food consumption on body weight, egg production and developmental time in Chaoborus crystallinus De Geer (Diptera: Chaoboridae). Oecologia 88, 470-476.

Butler, C.J., Tran, H.B., 2017. Dwarf Palmetto (Sabal minor) Population Increase in Southeastern Oklahoma. Castanea 82, 163-168.

Cerenius, L., Söderhäll, K., 2004. The prophenoloxidase-activating system in invertebrates. Immunol. Rev. 198, 116-126.

Clarke, M.W., Thompson, G.J., Sinclair, B.J., 2013. Cold tolerance of the Eastern subterranean termite, Reticulitermes flavipes (Isoptera: Rhinotermitidae), in Ontario. Environ. Entomol. $42,805-810$.

Colinet, H., Sinclair, B.J., Vernon, P., Renault, D., 2015. Insects in Fluctuating Thermal Environments. Annu. Rev. Entomol. 60, 123-140.

Costanzo, J.P., Moore, J.B., Lee, R.E., Kaufman, P.E., Wyman, J.A., 1997. Influence of soil hydric parameters on the winter cold hardiness of a burrowing beetle, Leptinotarsa decemlineata (Say). J. Comp. Physiol. - B Biochem. Syst. Environ. Physiol. 167, 169-176.

Danks, H. V., 2000. Dehydration in dormant insects. J. Insect Physiol. 46, 837-852.

Danks, H. V, 2002. Modification of adverse conditions by insects. Oikos 99, 10-24.

Diehl, J.M.C., Meunier, J., Holman, L., 2017. Surrounding pathogens shape maternal egg care but not egg production in the European earwig. Behav. Ecol. 1-9.

Downes, J.A., 1965. Adaptations of Insects in the Arctic. Annu. Rev. Entomol. 10, 257-274.

Estrella, N., Menzel, A., 2013. Recent and future climate extremes arising from changes to the bivariate distribution of temperature and precipitation in Bavaria, Germany. Int. J. Climatol. 33, 1687-1695.

Ferguson, L. V., Sinclair, B.J., 2017. Insect Immunity Varies Idiosyncratically During Overwintering. J. Exp. Zool. Part A Ecol. Genet. Physiol.

Fretwell, J., 1972. Populations in a Seasonal Environment. Princeton, NJ, NJ.

Gehrken, U., 1984. Winter survival of an adult bark beetle Ips acuminatus Gyll. J. Insect Physiol. 30, 421-429. 
Gillespie, J.P., Kanost, M.R., Trenczek, T., 1997. Biological mediators of insect immunity. Annu. Rev. Entomol 42, 611-643.

González-Santoyo, I., Córdoba-Aguilar, A., 2012. Phenoloxidase: A key component of the insect immune system. Entomol. Exp. Appl. 142, 1-16.

Hahn, D.A., Denlinger, D.L., 2011. Energetics of Insect Diapause. Annu. Rev. Entomol. 56, 103121.

Han, E.R.N., Bauce, E., 1998. Timing of diapause initiation, metabolic changes and overwintering survival of the spruce budworm, Choristoneura fumiferana. Ecol. Entomol. 23, 160-167.

Hodek, I., Hodková, M., 1988. Multiple role of temperature during insect diapause: a review. Entomol. Exp. Appl. 49, 153-165.

Huey, R.B., 1976. Temperature, Physiology, and the Ecology of Reptiles. Biol. Reptil. 12, 25-91.

Ingrisch, S., 1985. Effect of hibernation length on termination of diapause in European Tettigoniidae (Insecta: Orthoptera). Oecologia 65, 376-381.

Koch, L.K., Meunier, J., 2014. Mother and offspring fitness in an insect with maternal care: phenotypic trade-offs between egg number, egg mass and egg care. BMC Evol. Biol. 14, 125.

Kohlmeier, P., Dreyer, H., Meunier, J., 2015. PO-CALC: A novel tool to correct common inconsistencies in the measurement of phenoloxidase activity. J. Insect Physiol. 75, 80-84.

Kohlmeier, P., Holländer, K., Meunier, J., 2016. Survival after pathogen exposure in group-living insects: Don't forget the stress of social isolation! J. Evol. Biol. 29, 1867-1872.

Körner, M., Vogelweith, F., Foitzik, S., Meunier, J., 2017. Condition-Dependent Trade-Off Between Weapon Size and Immunity in Males of the European Earwig. Sci. Rep. 7, 7988.

Koštál, V., 2006. Eco-physiological phases of insect diapause. J. Insect Physiol. 52, 113-127.

Kramer, J., Thesing, J., Meunier, J., 2015. Negative association between parental care and sibling cooperation in earwigs: a new perspective on the early evolution of family life? J. Evol. Biol. 28, 1299-1308.

Krams, I., Daukšte, J., Kivleniece, I., Krama, T., Rantala, M.J., 2011. Overwinter survival depends on immune defence and body length in male Aquarius najas water striders. Entomol. Exp. Appl. 140, 45-51.

Lamb, R.J., 1976. Parental behaviour in the Dermaptera with special reference to Forficula auricularia. Can. Entomol. 108, 609-619.

Langston, R.L., Powell, J. a., 1975. The earwigs of California. Bull. Calif. Insect Surv. 20, 1-30.

Laughton, A.M., O'Connor, C.O., Knell, R.J., 2017. Responses to a warming world: Integrating life history, immune investment, and pathogen resistance in a model insect species. Ecol. Evol. 7, 9699-9710.

Lavine, M.D.D., Strand, M.R.R., 2002. Insect hemocytes and their role in immunity. Insect Biochem. Mol. Biol. 32, 1295-309.

Le Lann, C., Wardziak, T., van Baaren, J., van Alphen, J.J.M., 2011. Thermal plasticity of metabolic rates linked to life-history traits and foraging behaviour in a parasitic wasp. Funct. Ecol. 25, 641-651.

Lee, R.., Dellinger, D.., 1991. Insects at Low Temperatures. Chapman and Hall, New York, NY, NY. Lee Jr., R.E., 1991. Principles of Insect Low Temperature Tolerance, in: Lee Jr., R.E., Denlinger, D.L. (Eds.), Insects at Low Temperature. Springer US, Boston, MA, pp. 17-43.

Linderholm, H.W., 2006. Growing season changes in the last century. Agric. For. Meteorol. 137, $1-14$.

Linderman, J.A., Chambers, M.C., Gupta, A.S., Schneider, D.S., 2012. Infection-Related Declines in 
Chill Coma Recovery and Negative Geotaxis in Drosophila melanogaster. PLoS One 7.

Maczey, N., Edgington, S., Moore, D., Haye, T., 2016. Biology and host range testing of Triarthria setipennis and Ocytata pallipes (Diptera: Tachinidae) for the control of the European earwig (Forficula auricularia). Biocontrol Sci. Technol. 26, 447-461.

Marshall, K.E., Sinclair, B.J., 2015. The relative importance of number, duration and intensity of cold stress events in determining survival and energetics of an overwintering insect. Funct. Ecol. 29, 357-366.

Matter, S.F., Doyle, A., Illerbrun, K., Wheeler, J., Roland, J., 2011. An assessment of direct and indirect effects of climate change for populations of the Rocky Mountain Apollo butterfly (Parnassius smintheus Doubleday). Insect Sci. 18, 385-392.

Meunier, J., Kölliker, M., 2013. Inbreeding depression in an insect with maternal care: influences of family interactions, life stage and offspring sex. J. Evol. Biol. 26, 2209-2220.

Meunier, J., Wong, J.W.., Gómez, Y., Kuttler, S., Röllin, L., Stucki, D., Kölliker, M., 2012. One clutch or two clutches? Fitness correlates of coexisting alternative female life-histories in the European earwig. Evol. Ecol. 26, 669-682.

Montero, G.A., Lietti, M.M., 1998. Hibernacion de Calosoma argentinense (Coleoptera: Carabidae). Rev. Soc. Entomol. Argentina.

Morris, R.., Fulton, W.., 1970. Models for Development and Survival of Hyphantria cunea in Relation to Temperature and Humidity. Mem. Entomol. Soc. Canada 70, 1-60.

O’Brien, M.F., Kurczewski, F.E., 1982. Ethology and overwintering of Podalonia luctuosa (Hymenoptera: Sphecidae). Gt. Lakes Entomol. 15, 261-275.

Parmesan, C., 2006. Ecological and Evolutionary Responses to Recent Climate Change. Annu. Rev. Ecol. Evol. Syst. 37, 637-669.

Poyet, M., Havard, S., Prevost, G., Chabrerie, O., Doury, G., Gibert, P., Eslin, P., 2013. Resistance of Drosophila suzukii to the larval parasitoids Leptopilina heterotoma and Asobara japonica is related to haemocyte load. Physiol. Entomol. 38, 45-53.

Princé, K., Zuckerberg, B., 2015. Climate change in our backyards: The reshuffling of North America's winter bird communities. Glob. Chang. Biol. 21, 572-585.

Ramseyer, A., Boissy, A., Dumont, B., Thierry, B., 2009. Decision making in group departures of sheep is a continuous process. Anim. Behav. 78, 71-78.

Ratz, T., Kramer, J., Veuille, M., Meunier, J., 2016. The population determines whether and how life-history traits vary between reproductive events in an insect with maternal care. Oecologia 182, 443-452.

Ruf, T., Bieber, C., Arnold, W., Millesi, E., 2012. Living in a Seasonal World: Thermoregulatory and Metabolic Adaptations. Springer Berlin Heidelberg, Heidelberg.

Sadd, B.M., Siva-Jothy, M.T., 2006. Self-harm caused by an insect's innate immunity. Proc. Biol. Sci. 273, 2571-2574.

Salis, L., van den Hoorn, E., Beersma, D.G.., Hut, R.A., Visser, M.E., 2017. Photoperiodic cues regulate phenological carry-over effects in an herbivorous insect. Funct. Ecol. 0, 1-10.

Schebeck, M., Hansen, E.M., Schopf, A., Ragland, G.J., Stauffer, C., Bentz, B.J., 2017. Diapause and overwintering of two spruce bark beetle species. Physiol. Entomol. 42, 200-210.

Sinclair, B.J., 2015. Linking energetics and overwintering in temperate insects. J. Therm. Biol. 54, 5-11.

Sinclair, B.J., 2001. Field ecology of freeze tolerance: interannual variation in cooling rates, freeze-thaw and thermal stress in the microhabitat of the alpine cockroach Celatoblatta 
quinquemaculata. Oikos 93, 286-293.

Sperry, J.H., Weatherhead, P.J., 2012. Individual and sex-based differences in behaviour and ecology of rat snakes in winter. J. Zool. 287, 142-149.

Stålhandske, S., Lehmann, P., Pruisscher, P., Leimar, O., 2015. Effect of winter cold duration on spring phenology of the orange tip butterfly, Anthocharis cardamines. Ecol. Evol. 5, 55095520.

Strand, M.R., Pech, L.L., 1995. Immunological basis for compatibility in parasitoid-host relationships. Annu. Rev. Entomol. 40, 31-56.

Tatar, M., Yin, C.M., 2001. Slow aging during insect reproductive diapause: Why butterflies, grasshoppers and flies are like worms. Exp. Gerontol. 36, 723-738.

Tauber, M.J., Tauber, C.A., 1976. Insect Seasonality: Diapause Maintenance, Termination, and Postdiapause Development. Annu. Rev. Entomol. 21, 81-107.

Turnock, W.J., Fields, P.G., 2005. Winter climates and cold hardiness in terrestrial insects. Eur. J. Entomol. 102, 561-576.

Vitasse, Y., Signarbieux, C., Fu, Y.H., 2017. Global warming leads to more uniform spring phenology across elevations. Proc. Natl. Acad. Sci. 201717342.

Vogelweith, F., Körner, M., Foitzik, S., Meunier, J., 2017. Age, pathogen exposure, but not maternal care shape offspring immunity in an insect with facultative family life. BMC Evol. Biol. 17, 69.

Vogelweith, F., Thiery, D., Moret, Y., Moreau, J., 2013. Immunocompetence increases with larval body size in a phytophagous moth. Physiol. Entomol. 38, 219-225.

Williams, C.M., Henry, H.A.L., Sinclair, B.J., 2015. Cold truths: How winter drives responses of terrestrial organisms to climate change. Biol. Rev. 90, 214-235.

Williams, C.M., Ragland, G.J., Betini, G., Buckley, L.B., Cheviron, Z.A., Donohue, K., Hereford, J., Humphries, M.M., Lisovski, S., Marshall, K.E., Schmidt, P.S., Sheldon, K.S., Varpe, $\varnothing$., Visser, M.E., 2017. Understanding Evolutionary Impacts of Seasonality: An Introduction to the Symposium. Integr. Comp. Biol. 57, 921-933.

Williams, I.S., 1999. Slow-growth, high-mortality - a general hypothesis, or is it? Ecol. Entomol. 24, 490-495.

Young, J.H., Price, R.G., 1977. Overwintering of Heliothis zea in Southwestern Oklahoma. Environ. Entomol. 6, 627-628.

Zachariassen, K.E., 1985. Physiology of cold tolerance in insects. Physiol. Rev. 65, 799-832. 
Table 1. Effects of winter treatment, social treatment and their interaction on the hemocyte concentration, PO activity and total-PO activity. Note that female mass was added as a covariate to control for any effects on immunity. Significant P-values are in bold.

\begin{tabular}{|c|c|c|c|c|c|c|c|c|c|}
\hline & \multicolumn{3}{|c|}{$\begin{array}{c}\text { Hemocyte } \\
\text { concentration }\end{array}$} & \multicolumn{3}{c|}{ PO activity } & \multicolumn{3}{c|}{ Total-PO activity } \\
\cline { 2 - 10 } & $\mathrm{df}$ & $\mathrm{F}$ & $\mathrm{P}$ & $\mathrm{df}$ & $\mathrm{F}$ & $\mathrm{P}$ & $\mathrm{df}$ & $\mathrm{F}$ & $\mathrm{P}$ \\
\hline Female mass & 1,103 & 0.56 & 0.455 & 1,82 & 3.32 & 0.072 & 1,86 & 0.20 & 0.657 \\
\hline Winter length & 1,103 & 0.49 & 0.486 & 1,82 & 2.58 & 0.112 & 1,86 & 10.00 & $\mathbf{0 . 0 0 2}$ \\
\hline $\begin{array}{c}\text { Social treatment } \\
\text { Winter length } \times \text { Social } \\
\text { treatment }\end{array}$ & 3,103 & 2.77 & $\mathbf{0 . 0 4 6}$ & 3,82 & 0.89 & 0.452 & 3,86 & 0.52 & 0.668 \\
\hline \begin{tabular}{c} 
When \\
\hline
\end{tabular} & 4,103 & 4.48 & $\mathbf{0 . 0 0 5}$ & 3,82 & 1.22 & 0.308 & 3,86 & 1.00 & 0.397 \\
\hline
\end{tabular}


Table 2. Full summary depicting statistical differences in hemocyte count between all levels of both the winter treatments and the social treatments using post-hoc least-squares means corrected for multiple testing (Tukey method). Significant P-Values are in bold.

\begin{tabular}{|c|c|c|c|c|c|c|c|}
\hline & $\begin{array}{c}\text { Familiar group } \\
\text { unmanipulated } \\
\text { (Long winter) }\end{array}$ & $\begin{array}{l}\text { Familiar group } \\
\text { unmanipulated } \\
\text { (Short winter) }\end{array}$ & $\begin{array}{c}\text { Sudden } \\
\text { isolation } \\
\text { (Long winter) }\end{array}$ & $\begin{array}{c}\text { Sudden } \\
\text { isolation } \\
\text { (Short winter) }\end{array}$ & $\begin{array}{c}\text { Familiar group } \\
\text { - manipulated } \\
\text { (Long winter) }\end{array}$ & $\begin{array}{l}\text { Familiar group } \\
\text { - manipulated } \\
\text { (Short winter) }\end{array}$ & $\begin{array}{l}\text { Changing } \\
\text { group } \\
\text { (Long winter) }\end{array}$ \\
\hline $\begin{array}{l}\text { Changing group } \\
\text { (Short winter) }\end{array}$ & $p=0.103$ & $p=0.005$ & $p=0.857$ & $p=0.636$ & $p=0.886$ & $p=0.243$ & $p=0.017$ \\
\hline $\begin{array}{l}\text { Changing group } \\
\text { (Long winter) }\end{array}$ & $p=0.999$ & $p=0.999$ & $p=0.463$ & $p=0.632$ & $p=0.503$ & $p=0.944$ & \\
\hline $\begin{array}{c}\text { Familiar group - } \\
\text { manipulated } \\
\text { (Short winter) }\end{array}$ & $p=0.999$ & $p=0.752$ & $p=0.979$ & $p=0.998$ & $p=0.982$ & & \\
\hline $\begin{array}{c}\text { Familiar group - } \\
\text { manipulated } \\
\text { (Long winter) }\end{array}$ & $p=0.850$ & $p=0.269$ & $p=1.000$ & $p=0.999$ & & & \\
\hline $\begin{array}{l}\text { Sudden isolation } \\
\text { (Short winter) }\end{array}$ & $p=0.935$ & $p=0.363$ & $p=0.999$ & & & & \\
\hline $\begin{array}{l}\text { Sudden isolation } \\
\text { (Long winter) }\end{array}$ & $P=0.834$ & $p=0.226$ & & & & & \\
\hline
\end{tabular}




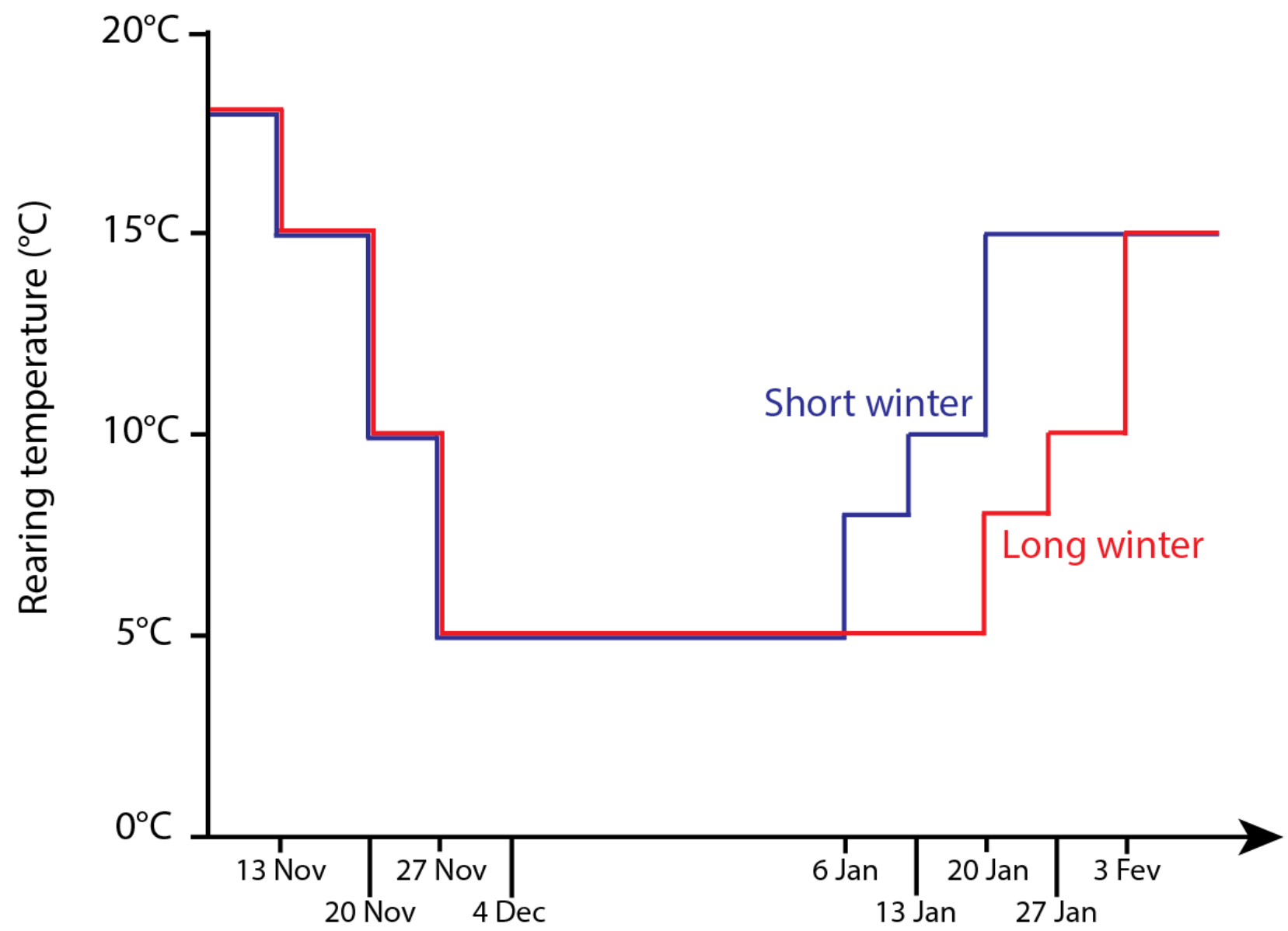

Figure 1. Detailed dates of temperature changes and durations of both the short winter (blue) and the long (red) winter treatments. 

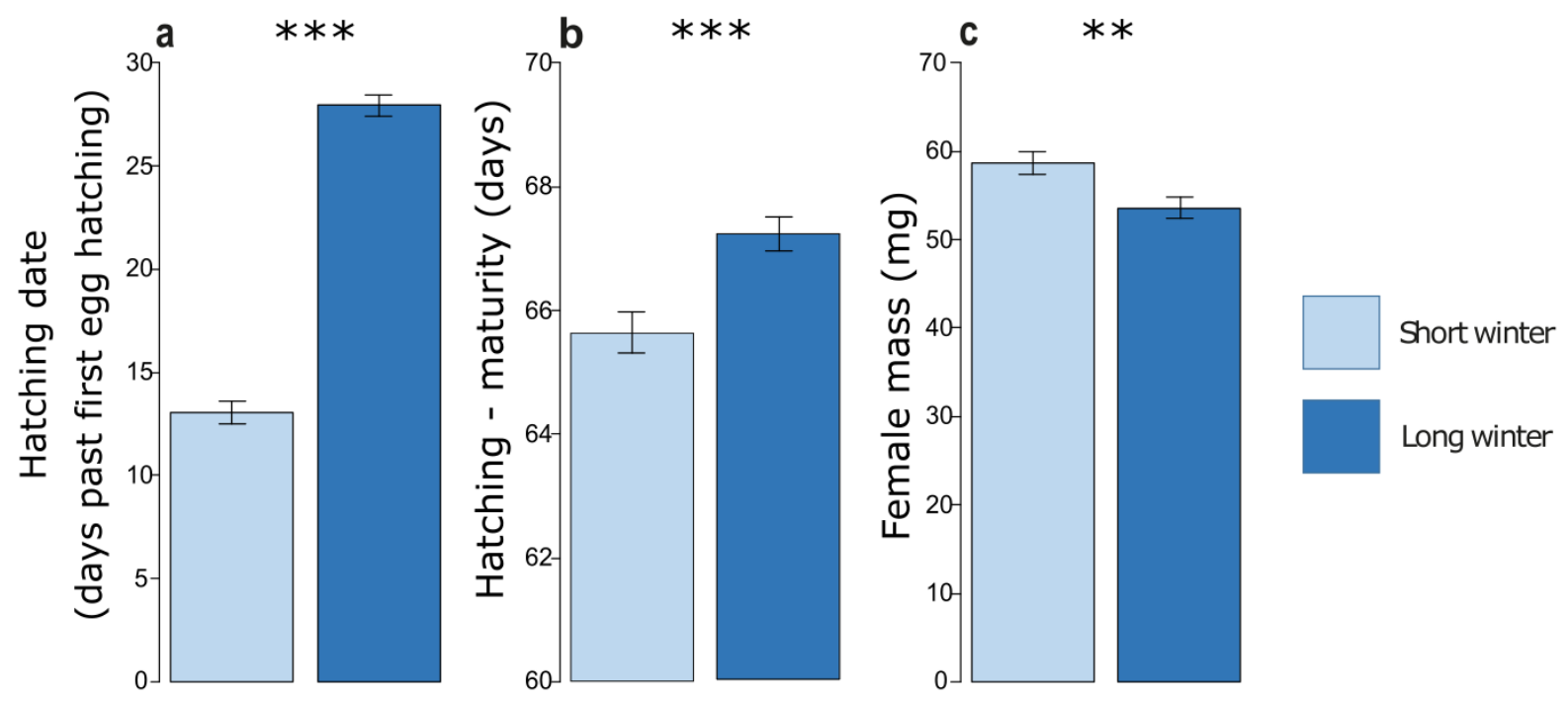

Figure 2. Effect of winter length on a) hatching date (the number of days a clutch hatched past the overall first egg hatching regardless of treatment), b) development time from hatching to maturity and c) female mass after the winter treatments at the beginning of the social treatments. Stars indicate significance, errors bars depict the standard error (SE). 


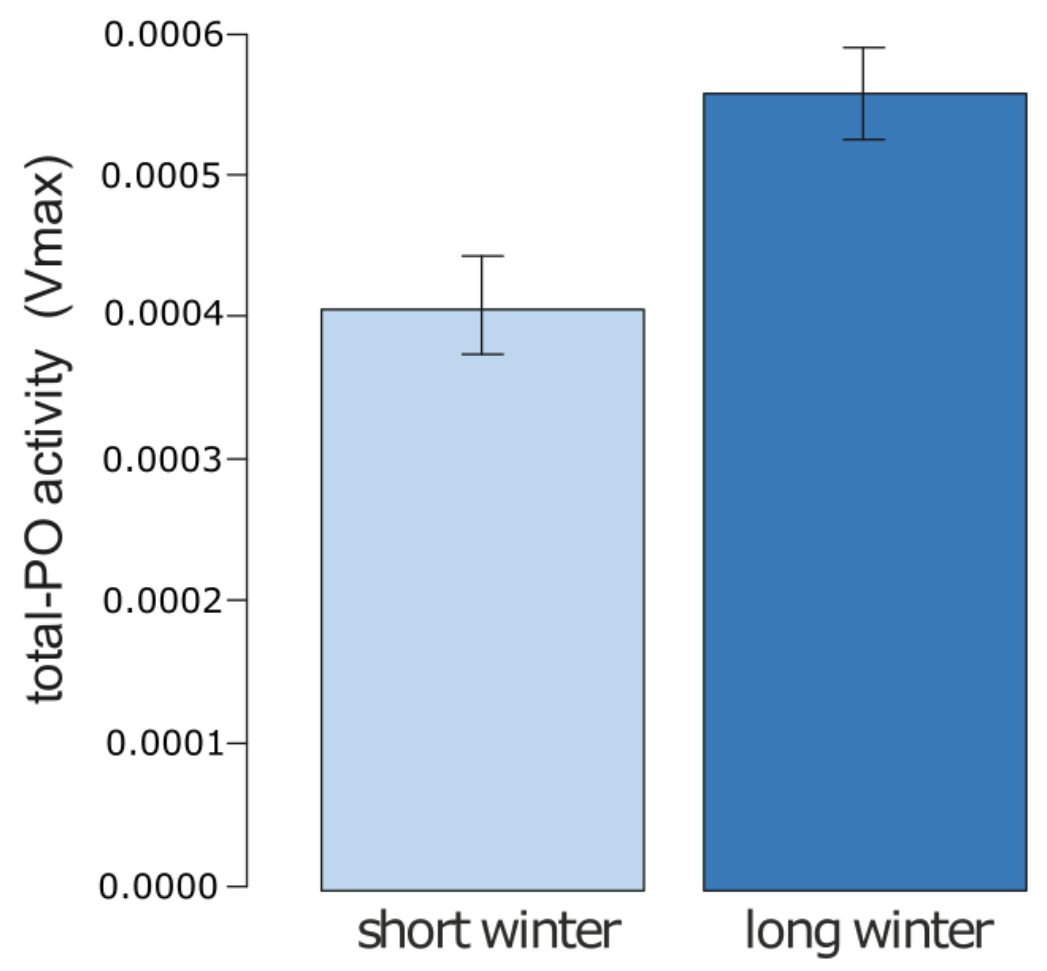

Figure 3. Effect of winter treatments on the total-PO activity of females. Values shown represent the reaction speed (Vmax) of the combined Phenoloxidase- and Prophenoloxidase in the individuals' hemolymph. Error bars depict the standard error (SE). 

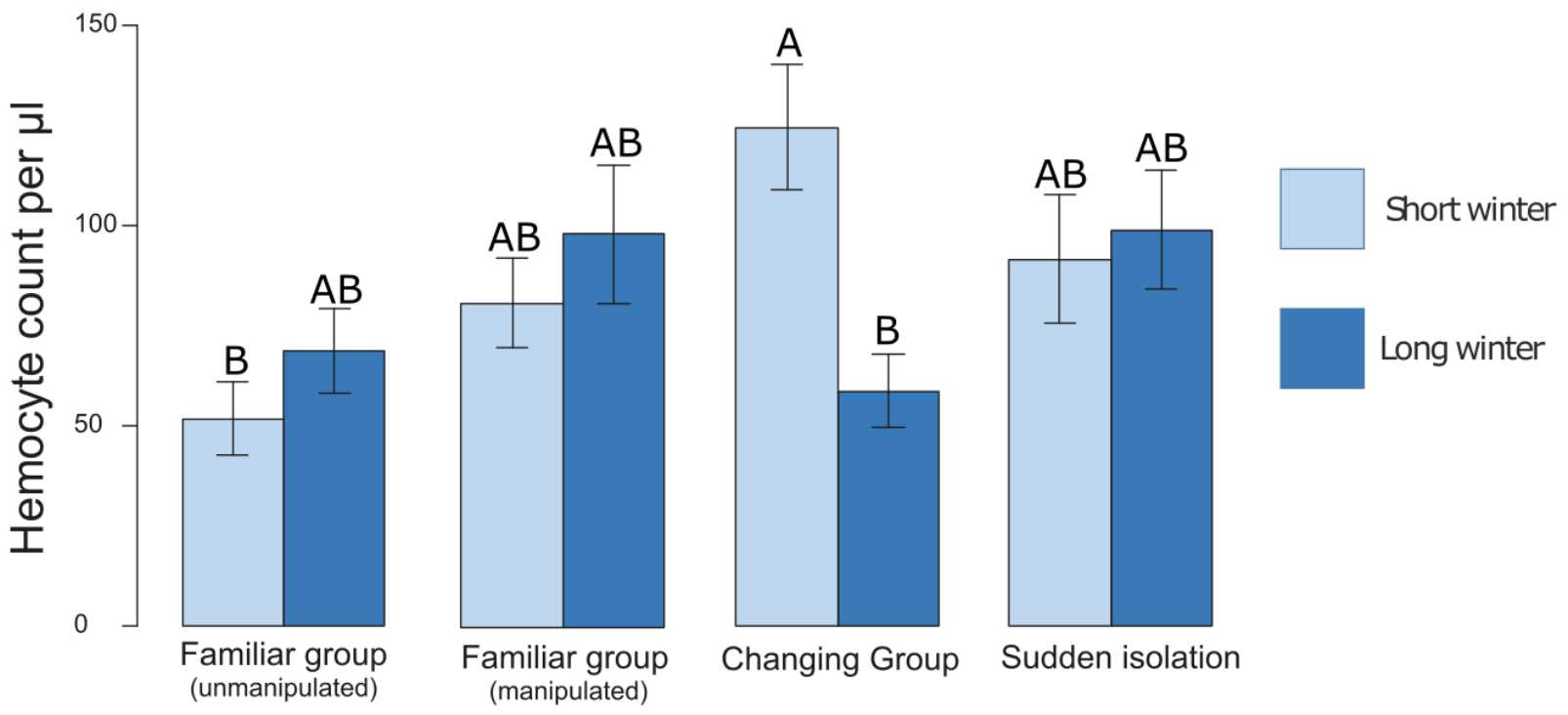

Figure 4. Showing the effect of an interaction between winter length and social treatment on female hemocyte count. Different letters indicate significance. Errors bars depict the standard error (SE). For all pairwise comparisons see Table S1. 